\title{
Quality of water and sediment in whiteleg shrimp (Litopenaeus Vannamei) pond
}

\author{
Bui Thi Bich Lien, Nguyen Thanh Giao*
}

\author{
College of Environment and Natural Resources, Can Tho University, Vietnam \\ *Corresponding Author
}

\begin{abstract}
Currently, the farming of saltwater and brackish water shrimps, especially whiteleg shrimp farming, is being interested and developed in terms of both area and level of intensive farming. This study was conducted to evaluate the environmental quality of water and sediment at the beginning and end of the pond of whiteleg shrimp. Water samples were collected to determine water quality indices including temperature, $\mathrm{pH}$, salinity (S), turbidity, dissolved oxygen (DO), total suspended solids (TSS), biochemical oxygen demand (BOD), chemical oxygen demand (COD), ammonium $\left(\mathrm{NH}_{4}^{+}-\mathrm{N}\right)$; nitrate $\left(\mathrm{NO}_{3}{ }^{-}-\mathrm{N}\right)$, total nitrogen (TN) and total phosphorus (TP). For sediment samples, organic matter (OM), total nitrogen (TN), total phosphorus (TP) were analyzed. The results showed that the water quality in the pond through the sampling periodswas mostly suitable for the growth of shrimp and within the allowed values of the regulations, except for salinity lower than QCVN 38: 2011/BTNMT and QCVN 02-19: 2014/BNNPTNT. Content of organic matters, total nitrogen, and total phosphorus accumulated in the bottom of the pond increased by $0.15 \%, 0.042 \%$, and $0.003 \%$ respectively. The study provides important information on water and sediment characteristics for shrimp pond management.
\end{abstract}

Keywords - sediment, water quality, whiteleg shrimp, nitrogen, phosphosrus.

\section{INTRODUCTION}

Aquaculture is one of the key economic sectors in Vietnamese agriculture, playing an important role in meeting the consumer demand and exporting to the world market. In recent years, white leg shrimp (Litopenaeusvannamei) are popularly cultured in Vietnam, because they have superior properties compared to tiger shrimp such as faster growth, better tolerance at high farming densitiesThe Mekong River Delta has a crisscrossing river system, long coastline with favorable climatic conditions for fisheries development and has become a key seafood production place, accounting for more than $90 \%$ of seafood quantity of the country. Aquaculture is rapidly developing, farming systems become more diverse. According to Soc Trang Department of Agriculture and Rural Development, the brackish water shrimp farming area in Vinh Chau town in 2019 is 7,695 ha, reaching over $32 \%$ of the plan (white leg shrimp is 6,077 ha, tiger shrimp is 1,618 ha). Shrimp farming not only contributes to increase seafood export, but also has a positive impact on socio-economic issues, improving the life of aquaculture farmers. However, white-leg shrimp are mainly cultured in intensive form, leading to more polluted environment and disease outbreaks and excessive antibiotic residues in shrimp meat, which greatly affects exports. Since then, water sources, pathogens, and risks in the farming process have become issues of concern. Currently, the quality of the environment in some fisheries areas is polluted due to ecological imbalance in coastal areas. This study was conducted to assess the environmental quality of water and sediment in the white leg shrimp pond to provide useful information for the environmental managers and shrimp's consumers.

\section{MATERIALS AND METHODS}

\subsection{Water sampling and analysis}

In white leg shrimp pond, samples were taken as pooled sample. After collecting samples, stored in a cool tank then the sample was transported to the laboratory of the College of Environment and Natural Resources for the analysis at the environmental quality laboratory. Temperature $(\mathrm{T}), \mathrm{pH}$, salinity (S\%), turbidity, dissolved oxygen (DO) parameters were measured directly in the field while the total suspended solids (TSS), biochemical oxygen demand (BOD), chemical oxygen demand (COD), ammonium $\left(\mathrm{NH}_{4}{ }^{+}-\mathrm{N}\right)$, nitrate $\left(\mathrm{NO}_{3}{ }^{-}-\mathrm{N}\right)$, total nitrogen $(\mathrm{TN})$ and total phosphorus (TP) were measured using the 
standard methods (APHA,1998). Surface water was assessed using QCVN 38: 2011/BTNMT, the quality of surface water to protect aquatic life.

\subsection{Sediment sampling and analysis}

The sediment sample was collected using petersengause and stored in plastic bag. The sample was dried at room temperature, crushed and sieved through the $0.5 \mathrm{~mm}$ pore size mesh to analyze organic matter, total nitrogen, and total phosphorus. Organic matter was analyzed by Walkley-Black dichromate method (Walkley-Black dichromate wet oxidation method), total nitrogen (TN) analyzed by Kjeldahl method, and total phosphorus (TP) analyzed by colorimetric method after digestion of the sample with mixture of $\mathrm{H}_{2} \mathrm{SO}_{4}$ and $\mathrm{HClO}_{4}$. The crushed soil sample $(0.5 \mathrm{~g})$ was digested using a microwave digester (Milestone, Ethos) using the method of the US Federal Environmental Protection Agency (EPA3051) by adding $10 \mathrm{ml}$ of $65 \%$ nitric acid and operating under 1,000 watts of electricity at $175^{\circ} \mathrm{C}$ for 15 minutes (Cui et al., 2010).

\section{RESULTS AND DISCUSSION}

\subsection{Water quality in the white leg shrimp pond}

\subsubsection{Temperature and $\mathrm{pH}$}

Temperature is the most important factor affecting aquaculture. Temperature affects most of the other parameters characteristic of water quality. During the first and second sampling sessions, the water temperature measured at 8:00 fluctuated between 32 and $34^{\circ} \mathrm{C}$ (Figure $1)$.

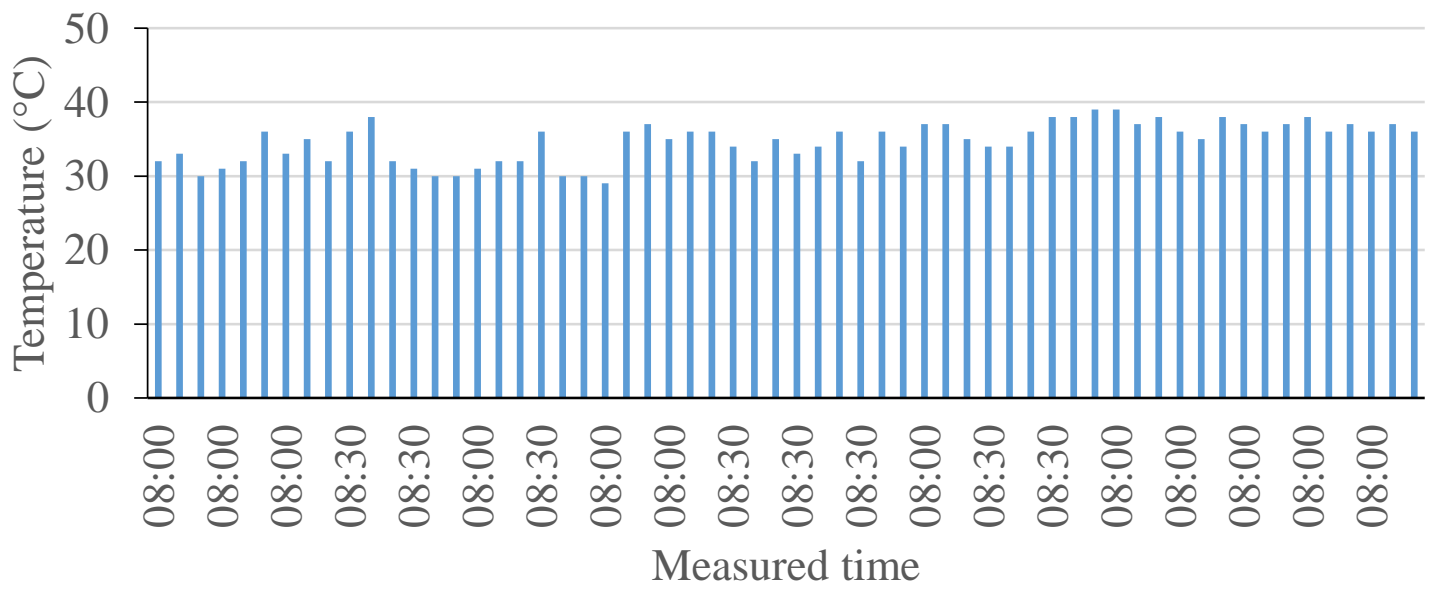

Fig.1: Daily measurement of temperature in the shrimp pond

According to QCVN 02-19:2014/BNNPTNT, the allowable temperature in white leg shrimp pond water is $18-33^{\circ} \mathrm{C}$. From the above results, it shows that the water temperature in shrimp ponds over 2 sampling phases was higher than QCVN 02-19:2014/BNNPTNT. The sample measurement results showed that the $\mathrm{pH}$ value in shrimp pond water through the sampling times ranged from 8.1-8.2 (Figure 2). A small change in $\mathrm{pH}$ also affects shrimp, because $\mathrm{pH}$ is one of the environmental factors affecting aquatic organisms, when the environmental $\mathrm{pH}$ is too high or too low is detrimental to the growth of aquatic life. In water environment, $\mathrm{pH}$ changes due to hot weather or heavy rain. According to QCVN 02-19:2014/BNNPTNT, the permissible $\mathrm{pH}$ value in the pond water of black tiger shrimp and white leg shrimp is 7-9 and the daily fluctuation is not more than 0.5 . In general, the average $\mathrm{pH}$ value in shrimp pond water over 2 sampling sessions was relatively suitable for shrimp growth and development and is within the allowable limits of this regulation. 


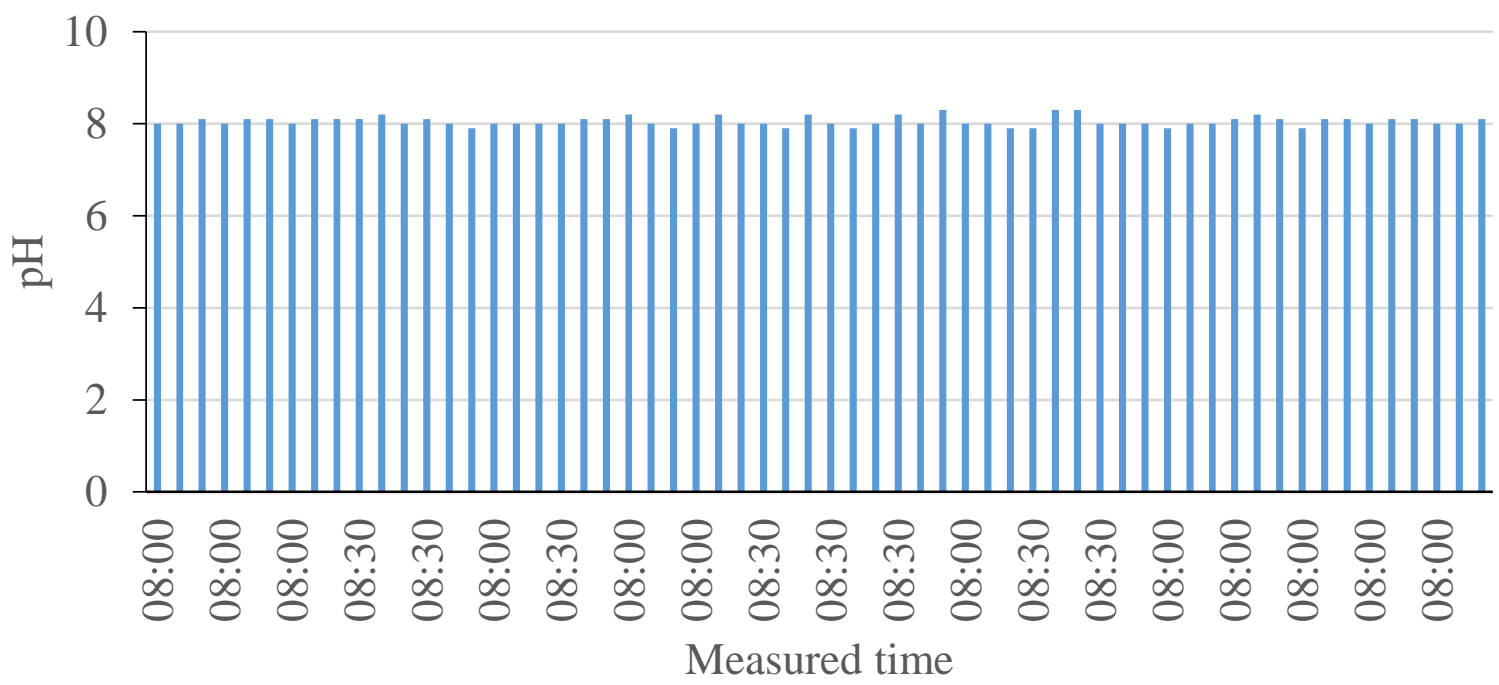

Fig.2: Daily measurement of $p H$ in the shrimp pond

\subsubsection{Dissoloved oxygen and salinity}

The average dissolved oxygen concentration in the water of the shrimp pond over the two sampling cycles ranged from 5.8 to $6.6 \mathrm{mg} / \mathrm{L}$ (Figure 3). Dissolved oxygen concentrations in the pond water in the second collection time was lower. This happened since the oxygen demand increases as there is more shrimp feed and waste accumulated in the bottom of the pond over time. Dissolved oxygen in the pond is usually consumed by the living activities of shrimp, fish, shrimp size, organic matter decomposition by microorganisms and other organisms living in the pond environment. According to QCVN 02-19: 2014/BNNPPTNT, the permitted concentration of dissolved oxygen in shrimp pond water is greater than 3.5 $\mathrm{mg} / \mathrm{L}$. Therefore, the dissolved oxygen concentration through the sampling sessions was relatively consistent with this standard.

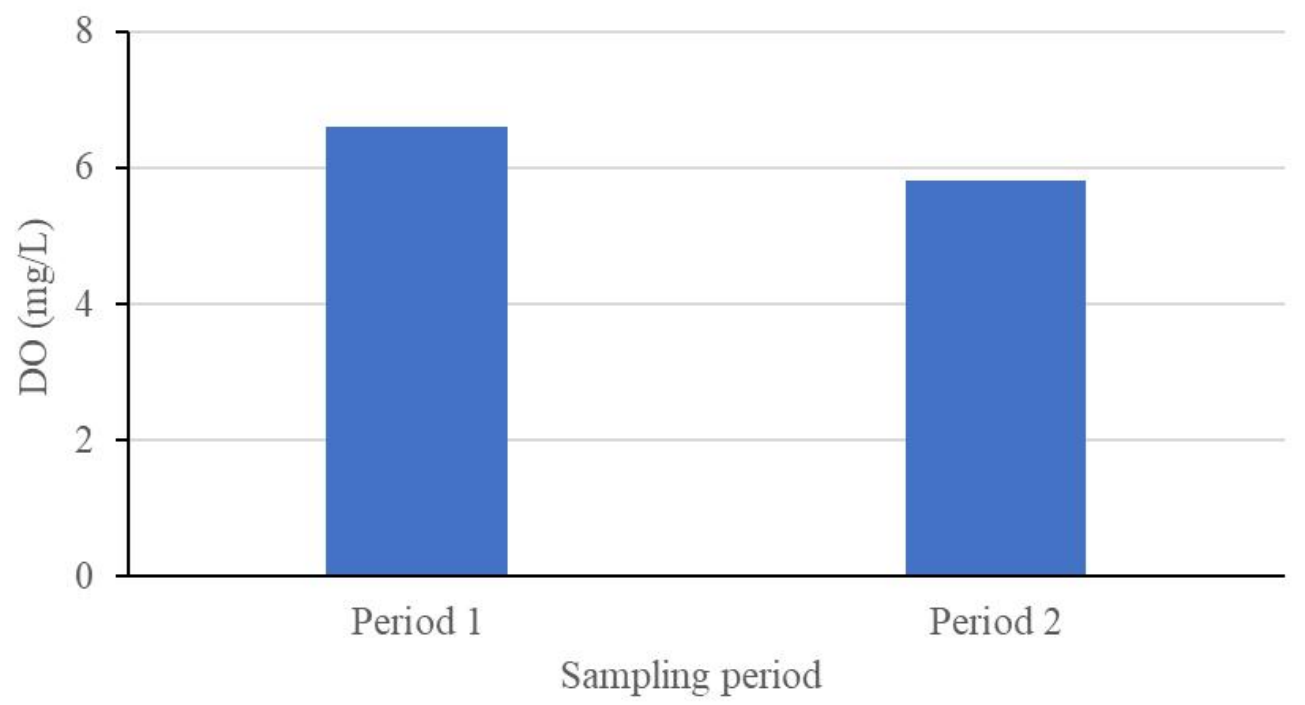

Fig.3: DO in the shrimp pond

The survey showed that the salinity in the shrimp pond water through the sampling sessions tended to decrease. The mean salinity values ranged from 4.5-5 \%o (Figure 4). The reason for the decrease in salinity is that the water level in the pond decreases, the hot sun evaporates during the ISSN: 2456-1878

https://dx.doi.org/10.22161/ijeab.55.19 culture process, making the salinity increase. According to QCVN 02-19: 2014/BNNPTNT, the permissible salinity in the shrimp ponds is 5-35\%o. From the results of this study, it showed that the salinity in shrimp pond water in the second sampling phase was not consistent with this standard. 


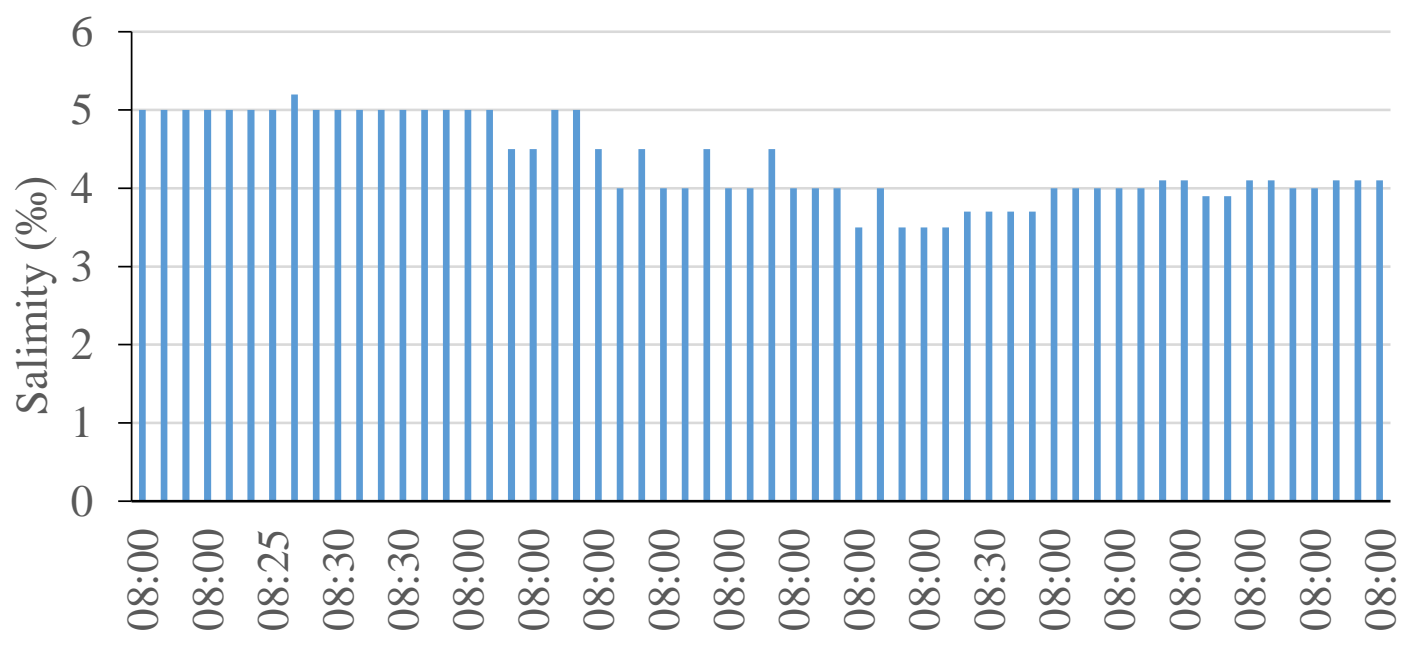

\section{Measured time}

Fig.4: Daily measurement of salinity in the shrimp pond

\subsubsection{Turbidity and total suspended solids}

Water turbidity is related to the amount of material suspended in the water, which is its ability to block the sun's light. High turbidity reduces sunlight penetration into water, reduces oxygen production in the pond. The results of analyzing turbidity through 2 collection times showed that the first collection time turbidity was $12,515 \mathrm{NTU}$ and the second time was 13.1 NTU (Figure 5), it showed that after 3 month, the turbidity increased to $0.585 \mathrm{NTU}$, the main reason could be due to the shrimp activities, food left and phytoplankton causing increasing turbidity.

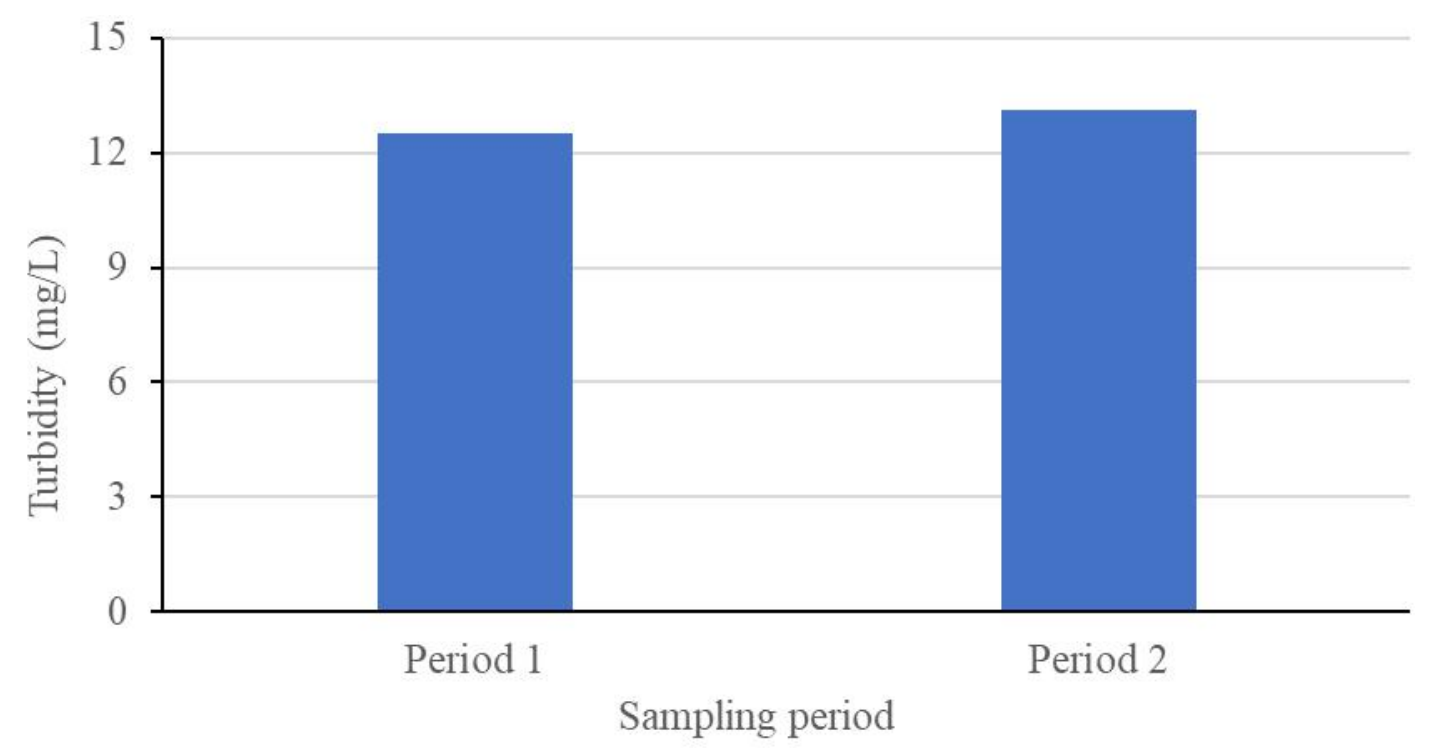

Fig.5: Turbidity in the shrimp pond

The average TSS concentration of the shrimp pond over 2 sampling cycles ranged from 20-22 mg/L (Figure 6). The increase in total suspended solids in the pond depends on the amount of phytoplankton, soil erosion, feed added to the pond, and mechanical movements in the pond (shrimp movement, waves). In general, TSS in the study pond water was suitable for shrimp development, so TSS in the pond is not a factor affecting the culture environment and shrimp yield. According to QCVN 38: 2011/BTNMT, TSS value in surface water for the purpose of protecting aquatic life is 


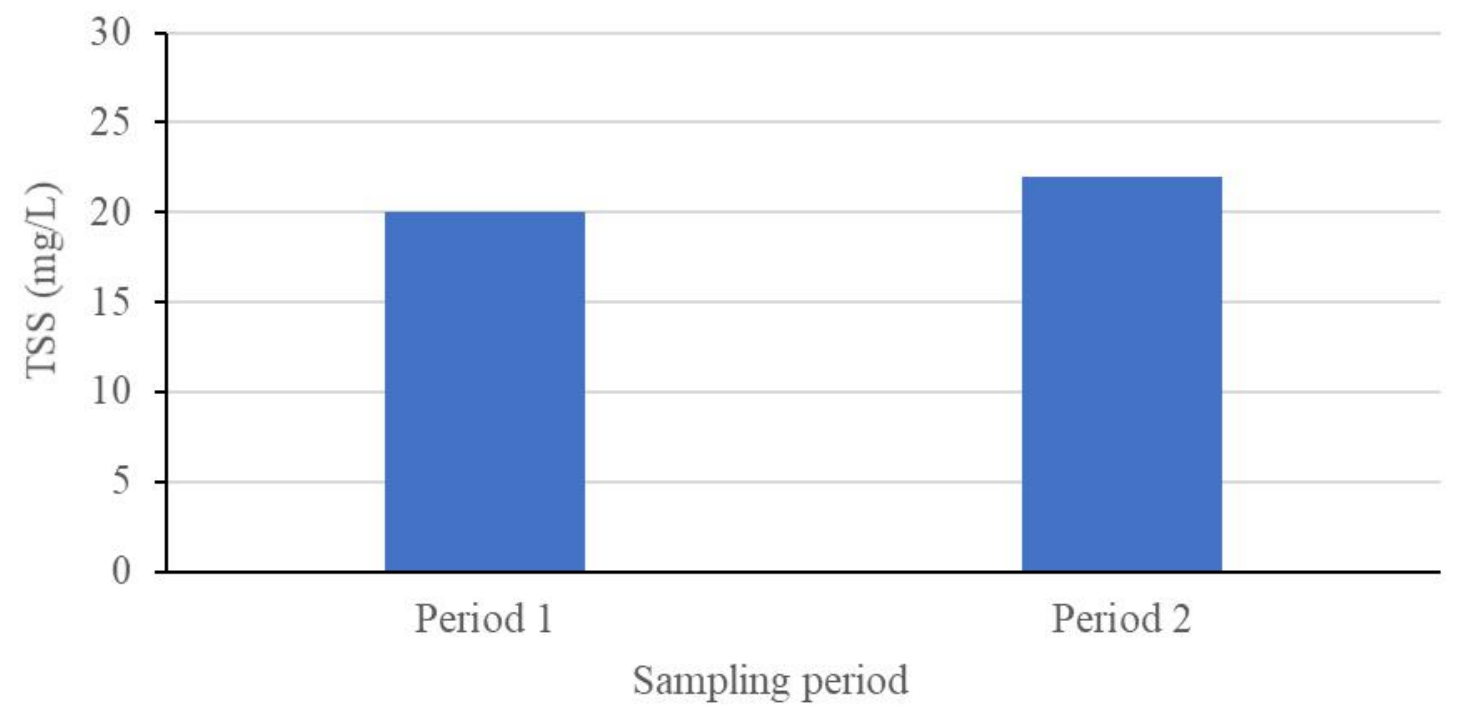

Fig.6: TSS in the shrimp pond

\subsubsection{Chemical and biological oxygen demands}

The results of COD in the pondwater showed that COD tended to decrease. At the beginning of the cultivation, COD concentration was $8.64 \mathrm{mg} / \mathrm{L}$, but decreased to $7.8 \mathrm{mg} / \mathrm{L}$ at the third month (Figure 7).

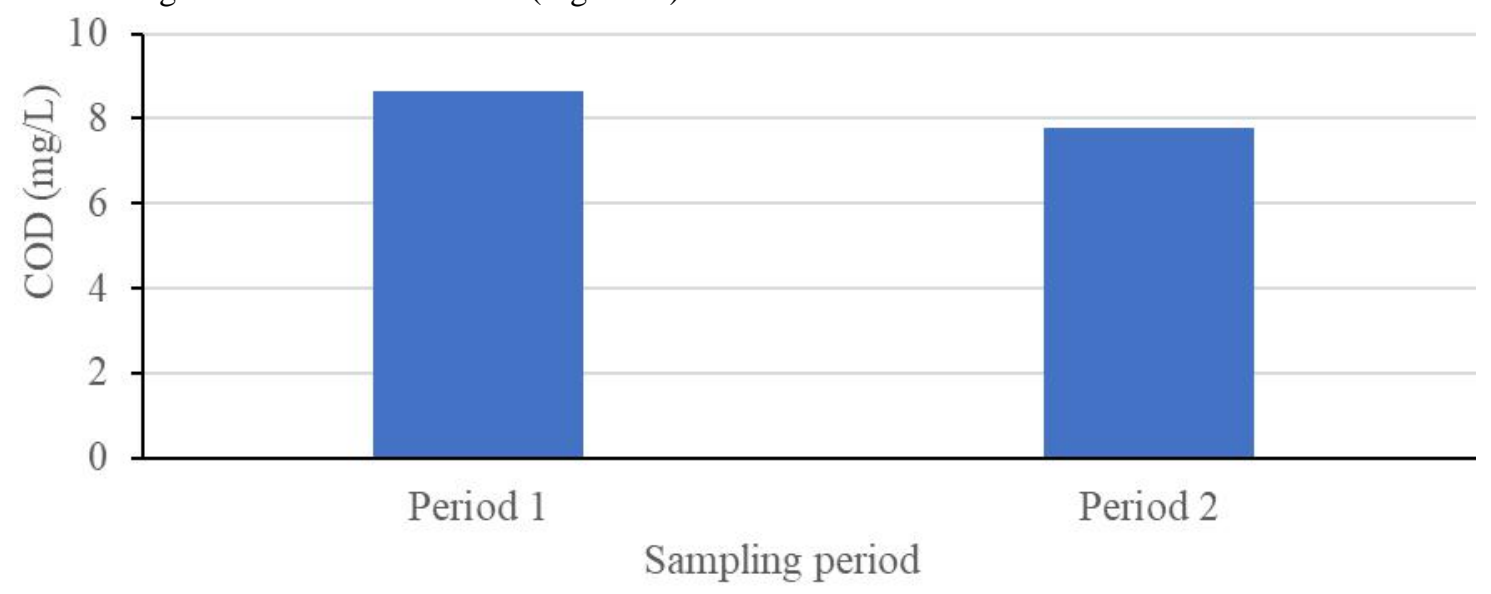

Fig.7: COD in the shrimp pond
According to Smith et al. (2002) and Boyd (1998), the COD concentration in shrimp ponds should be controlled below $20 \mathrm{ppm}(20 \mathrm{mg} / \mathrm{L})$. As could be seen that the concentration of COD classified the water in the shrimp pond clean when COD ranges from 6-20 mg/L (Be, 1995).
The concentration of BOD fluctuatedin the ranges of 3.04-3.28 $\mathrm{mg} / \mathrm{L}$, the results of the second sampling time was lower than that in the first 1 (Figure 8). A typical aquaculture pond has a BOD value of $5-20 \mathrm{mg} / \mathrm{L}$, higher BOD causes the higher the level of rich organic matter. 


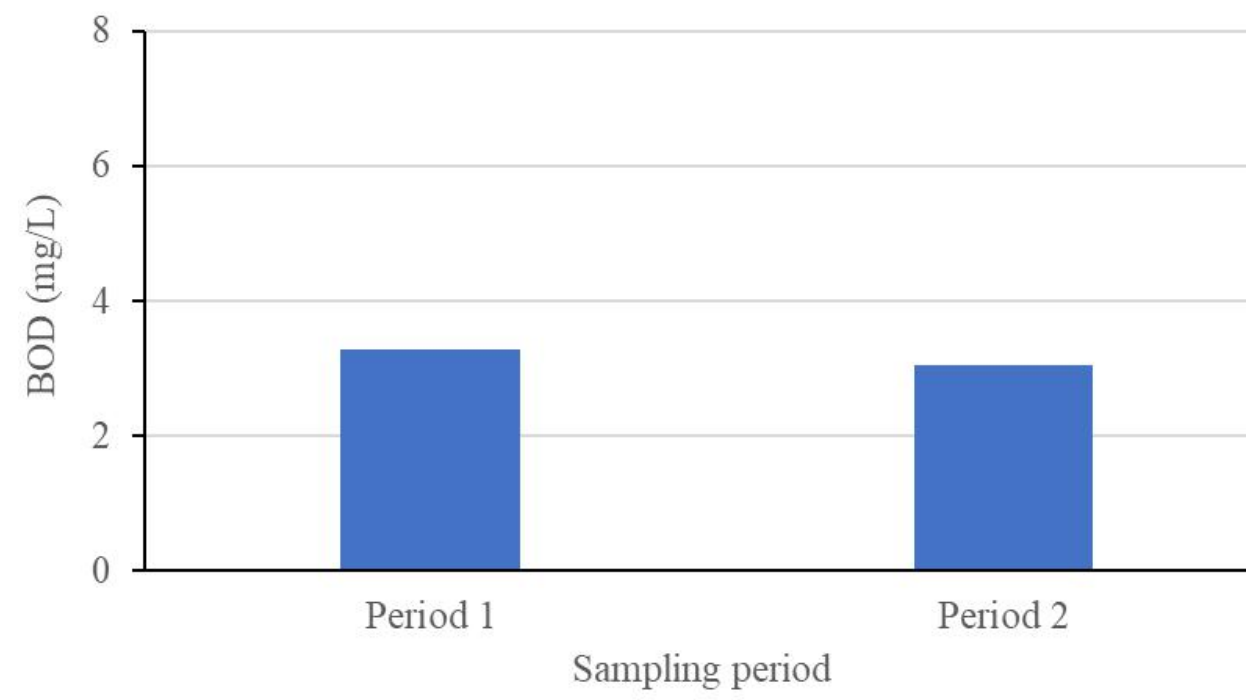

Fig.8: BOD in the shrimp pond

\subsubsection{Ammonia and nitrate}

The amonia concentration of the first sample was $0.386 \mathrm{mg} / \mathrm{L}$ and the second one was $0.188 \mathrm{mg} / \mathrm{L}$ (Figure 9). This could be because the conversion of organic nitrogen to nitrite and nitrate taking place in the shrimp pond. The process is governed by the $\mathrm{pH}$ value. The high ammonia concentration could harm shrimp growth and production.

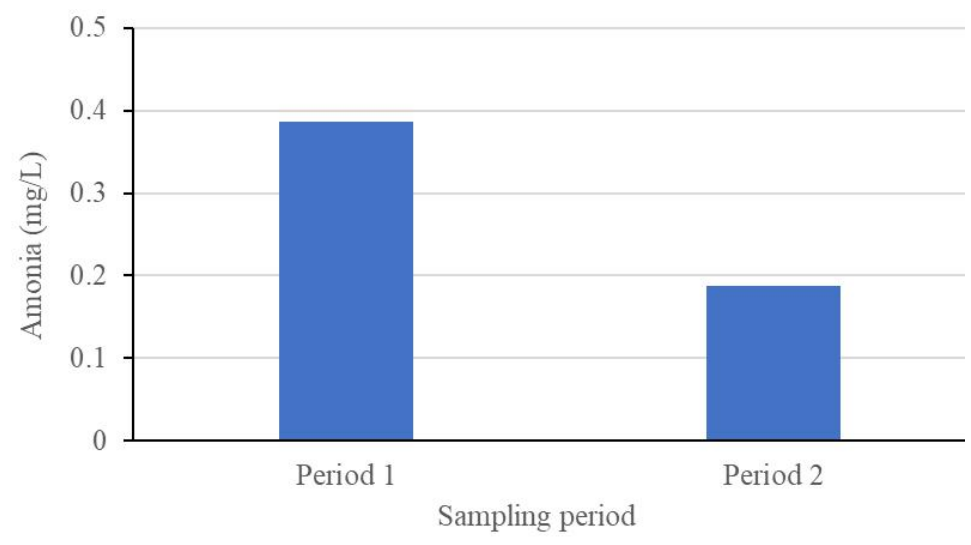

Fig.9: Ammonia in the shrimp pond

The average nitrate concentration of the shrimp pond over 2 sampling times ranged from 0.058-0.286 mg/L (Figure 10). Nitrate in the second sampling time was higher than the first one showed that after 3 month, the pollution level of the pond decreased compared to the beginning. 


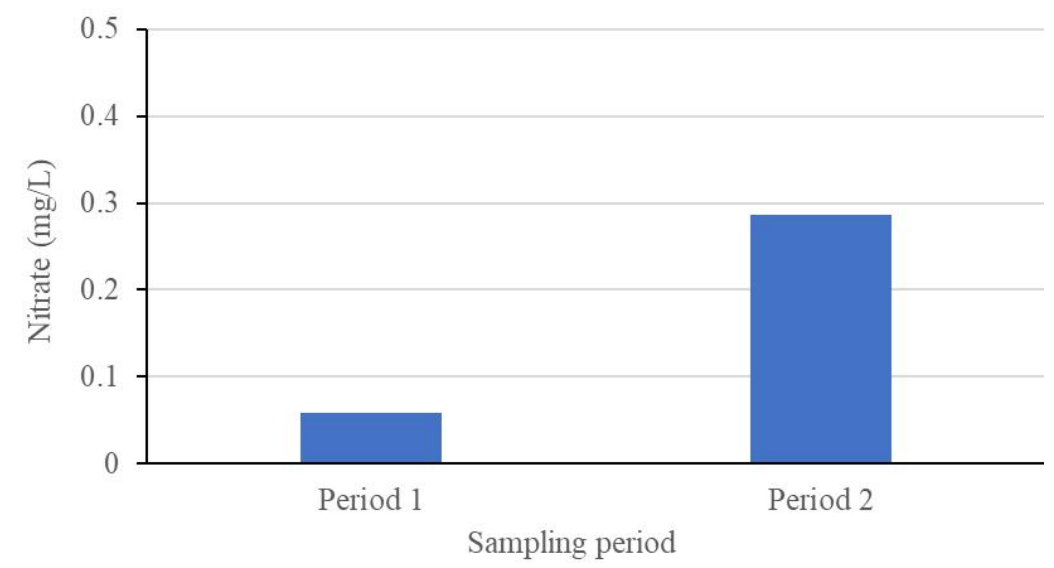

Fig.10: Nitrate in the shrimp pond

\subsubsection{Total nitrogen and phosphorus in the shrimp pond}

The results showed that the concentration of $\mathrm{TN}$ fluctuated in the range of 2,289-2,993 mg/L (Figure 11). In intensive shrimp ponds, nitrogen supplied to aquatic animals is the nitrogen in synthetic feeds. Normally, shrimp only absorb $25 \%$ of nitroen or $75 \%$ of the amount of nitrogen that is dispersed into the water as waste. Feed added to the pond is the main factor affecting the amount of nitrogen in the pond stored in the pond. Nitrogen storage in aquaculture ponds is relatively large depending on the nature of the pond, the efficiency of feed use, feed source and density of cultured shrimp.

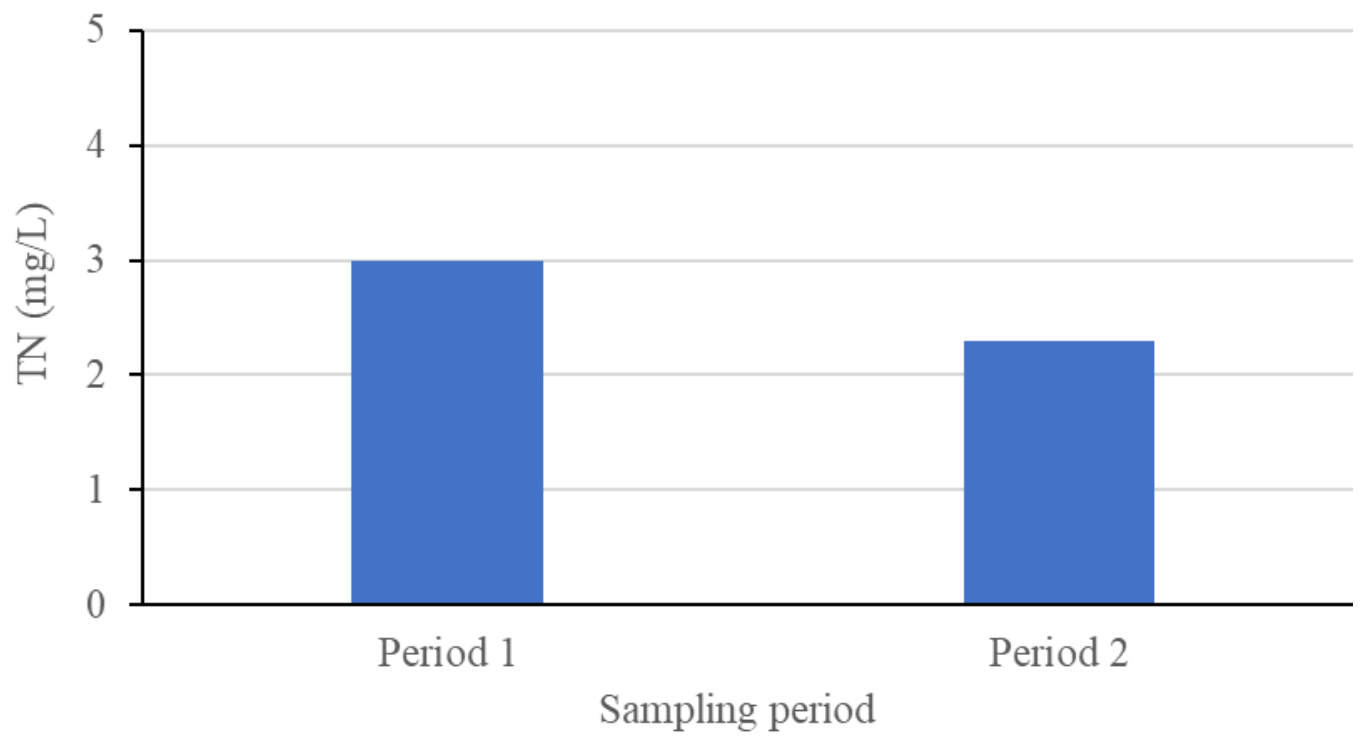

Fig.11: Total nitrogen in the shrimp pond

Phosphorus in the studying pond after 90 days of culture ranged from $0.02-0.03 \mathrm{mg} / \mathrm{L}$ (Figure 12). Due to the dissolution of the food, the deposited organic matter is decomposed by microorganisms and released phosphorus into the water, causing phosphorus concentration in the water to increase over time. In addition, according to Boyd (1998), after the floating plants die, $20-30 \%$ of the total phosphorus in their body decomposes into dissolved inorganic salts and $30-40 \%$ in dissolved organic form. The decomposition of phytoplankton after death and the release from food to phosphorus forms and increased total phosphorus concentration after the second sampling. According to Manh (2010) total phosphorus concentration in water in intensive shrimp ponds was from the beginning to the end of the crop ranged from 0.1 to $0.15 \mathrm{mg} / \mathrm{L}$. 


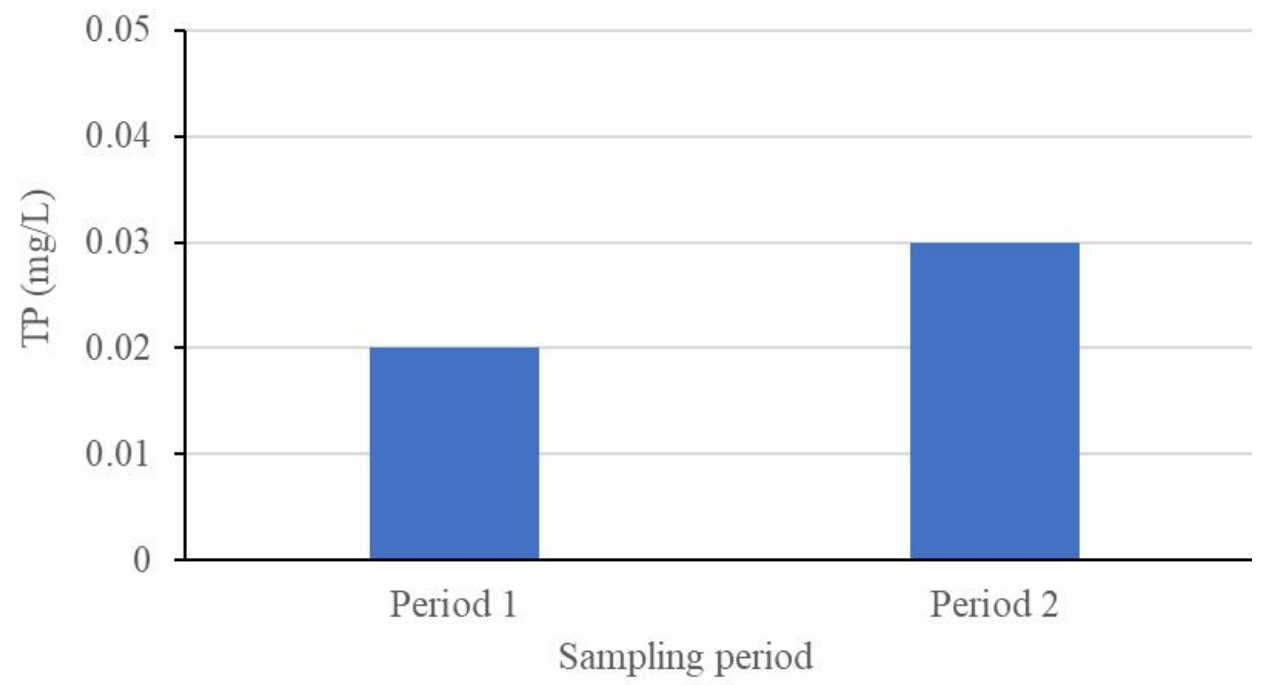

Fig.12: Total phosphorus in the shrimp pond

\subsection{Quality of sediment in the shrimp pond}

\subsubsection{Organic matters}

The amount of organic matter in the sediment increased and ranged from 1,047 to $1,197 \%$ (Figure 12). Organic matters in the sediment increases over time due to feed input during culture, partly converted from shrimp waste such as manure and molting and partly dissolved in water and in sediment. Organic matter is one of the reasons affecting the management of the shrimp pond and directly on the shrimp, the organic matter that is deposited on the pond bottom reduces the shrimp habitat area, their decomposition also causes dangerous for the lives of shrimp through generating toxic gases such as $\mathrm{NH}_{3}, \mathrm{H}_{2} \mathrm{~S}$ at the bottom.

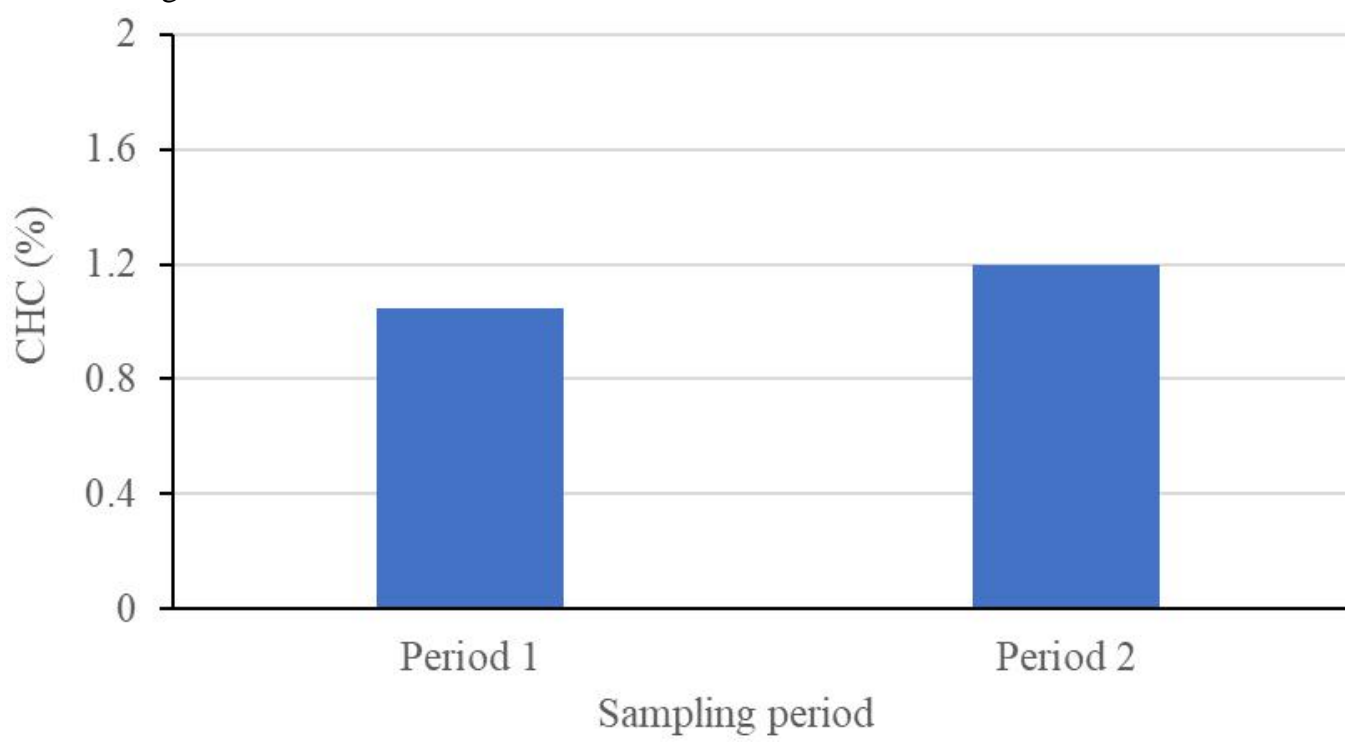

Fig.13: Organic matters in the shrimp pond

\subsubsection{Total nitrogen in the shrimp pond}

It was shown that nitrogen content in the sediment ranged from $0.062-0,104 \%$ (Figure 14). When the culture period is longer, the total nitrogen in the pond sediment increases due to the supply of nutrients from outside. The amount of nitrogen at the bottom of the pond depends greatly on the amount of stored organic matter: uneaten feed sources, shrimp waste products, the efficiency of using microorganisms is the cause of the nitrogen content in the pond bottom to increase. 


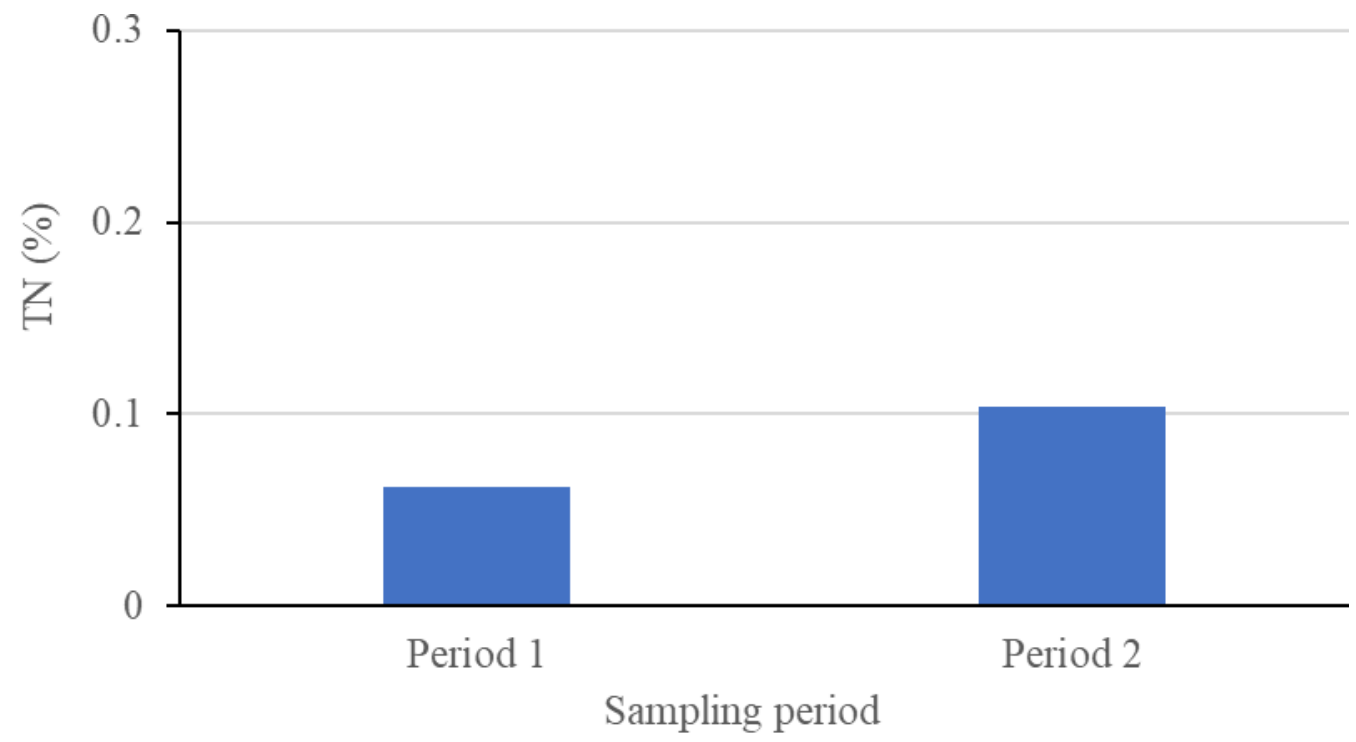

Fig.14: Total nitrogen in the shrimp pond

\subsubsection{Total phosphorus in the shrimp pond}

Phosphorus content at the bottom also increased over time of culture, ranging from 0.197 to $0.2 \%$ as $\mathrm{P}_{2} \mathrm{O}_{5}$ (Figure 15). Excess food, soil environmental characteristics, microbial decomposition, material conversion cycle in the pond are factors affecting phosphorus accumulation in the pond bottom. During the farming process, shrimp wastes and dead bodies of aquatic species settle on the pond bottom each day, together with the periodic fertilization in the pond, creating phosphorus in the pond bottom. Input phosphorus from a fertilizer or food source is first dissolved and hydrolyzed into a dissolved phosphate form. The amount of phosphorus dissolved in water would decrease rapidly as algae absorb and settle into the bottom mud layer. Aquatic animals also excrete a major amount of phosphorus in feces. Some of the phosphorus in algae or humus is also consumed by the plankton and excreted in the form of feces. Before being absorbed, all forms of phosphorus are converted to single phosphate, single phosphate is capable of participating in many chemical reactions: reacting with calcium, iron and aluminum. The reaction products have low solubility and are deposited into the sediment. These are the causes of phosphorus accumulation and increasing phosphorus in pond bottom sediment in the second sampling period.

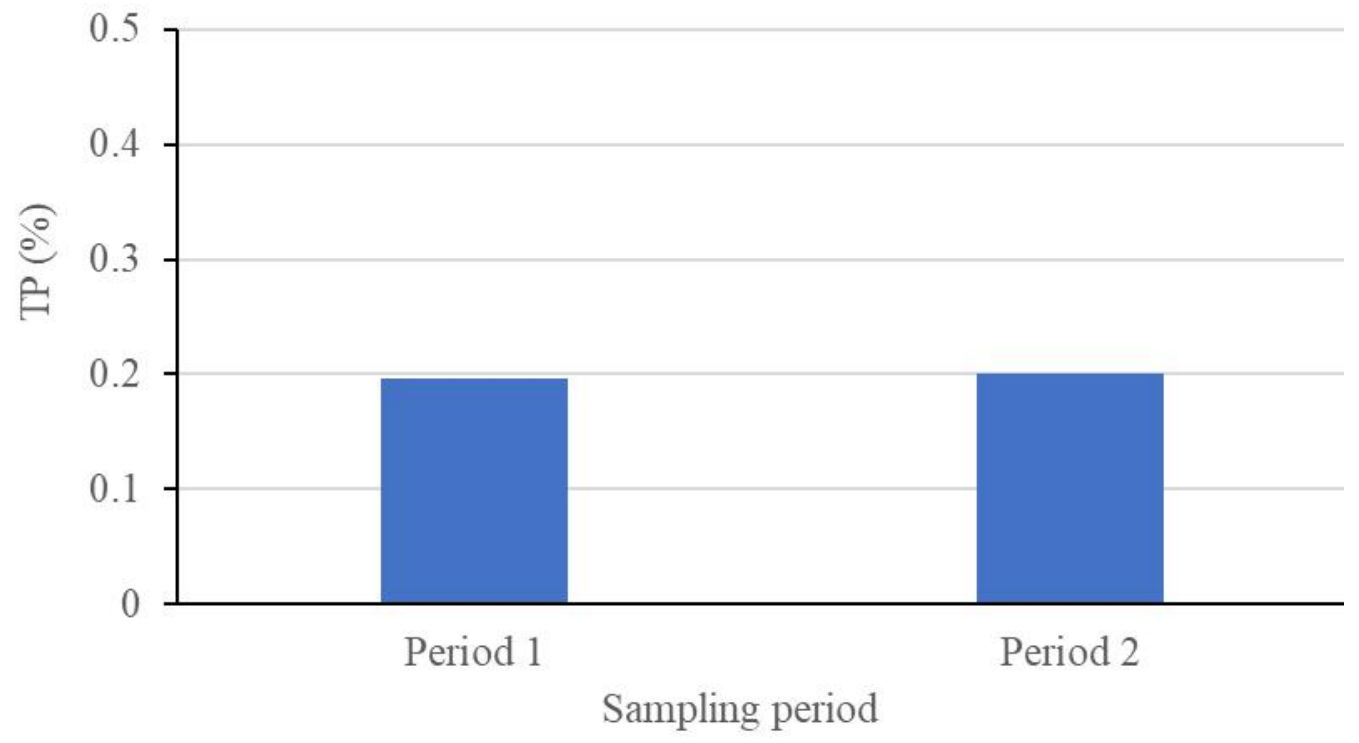

Fig.15:Total phosphorus in the shrimp pond 


\section{CONCLUSION}

Water quality parameters in the pond including temperature, $\mathrm{pH}, \mathrm{BOD}, \mathrm{TSS}, \mathrm{COD}, \mathrm{TP}, \mathrm{TN}$ through sampling period were mostly suitable for the growth of shrimp and were within the allowed areas of regulations QCVN 38: 2011/BTNMT and QCVN 02-19: 2014/BNNPTNT. Content of organic matter, nitrogen, phosphorus accumulated in pond sediment after 90 days increased by $0.15 \%, 0.042 \%$, and $0.003 \%$, respectively. At present, the model of shrimp culture according to the process that the water was not changed and supplying water to the pond was only one timethus reducing harvesting time and reducing harm to outside environment. This whiteleg shrimp farming model with little impact on the water and soil environment if it is well managed. However, appropriate treatment measures are needed for treating wastewater from the shrimp pond to sustain the environment.

\section{REFERENCES}

[1] American Public Health Association. Standard Methods for the Examination of Water and Wastewater, 20th edition, Washington DC, USA; 1998.

[2] Boyd, C. E. 1998. Water quality for pond Aquaculture. Deparment of Fisheries and Allied Aquaculture Auburn University, Alabama 36849 USA.

[3] Kungvankij, P., T.E. Chua, J. Pudadera, G. Corre, L.B. Tiro, I.O. Potestas, G.A. Taleon and J.N. Paw, 1986. Shrimp culture: pond design, operation and management. NACA training manual series. 2:50-68.

[4] QCVN 02-19:2014/BNNPTNT. National Technical Regulation on Brackish Water Shrimp Farming - Conditions for ensuring veterinary hygiene, environmental protection and food safety.

[5] QCVN 38:2011/BTNMT. National technical regulation on surface water quality protecting aquatic life

[6] Nguyen Van Manh, 2010. Effect of intensive farming techniques of giant tiger shrimp (Penaeus monodon) on pond sediment. Master thesis specializing in environmental science. Can Tho university. Trang 6, 42.

[7] Cui, B., Zhao, H., Lia, X., Zhang, K., Rena, H., Bai, J., 2010. Temporal and spatial distributions of soil nutrients in Hani terraced paddy fields, Southwestern China. Procedia Environmental Sciences 2 (2010) 1032-1042. 